\title{
Efficacy of a dementia intensive support (DIS) service at preventing admissions to medical and psychiatric wards: qualitative and quantitative evaluation
}

\author{
Judy S. Rubinsztein, ${ }^{1,2}$ (1) Catherine Hatfield, ${ }^{1}$ Liam High, ${ }^{1}$ Ramesh Krishnan, ${ }^{1}$ Nikitas \\ A. Arnaoutoglou, ${ }^{1,2,3}$ Panagiota Goulia, ${ }^{1}$ Robert Dudas, ${ }^{1,2}$ Shamim Ruhi, ${ }^{1}$ Karel Wildschut, \\ Leonidas Chouliaras, ${ }^{2}$ Benjamin R. Underwood ${ }^{1,2}$
}

BJPsych Bulletin (2020) 44, 261-265, doi:10.1192/bjb.2020.24

\author{
${ }^{1}$ Cambridgeshire and Peterborough NHS \\ Foundation Trust, Cambridge, UK: \\ ${ }^{2}$ Department of Psychiatry, University of \\ Cambridge, UK; ${ }^{3}$ Aristotle University of \\ Thessaloniki, Greece \\ Correspondence to Judy S. Rubinsztein \\ (judy.rubinsztein@cpft.nhs.uk) \\ First received 22 Aug 2019, final revision \\ 4 Feb 2020, accepted 26 Feb 2020 \\ (c) The Authors 2020. This is an Open \\ Access article, distributed under the \\ terms of the Creative Commons \\ Attribution-NonCommercial- \\ NoDerivatives licence (http:// \\ creativecommons.org/licenses/by-nc \\ nd/4.0/), which permits non-commercial \\ re-use, distribution, and reproduction in \\ any medium, provided the original work is \\ unaltered and is properly cited. The \\ written permission of Cambridge \\ University Press must be obtained for \\ commercial re-use or in order to create a \\ derivative work.
}

Aims and method To establish whether a dementia intensive support (DIS) service that is part of a crisis resolution and home treatment team for older people is preventing admissions to acute hospital and psychiatric wards. The number of referrals in 2017 to the DIS service was established and those admitted to hospital ascertained. Senior doctors examined 30 sets of notes in detail and reached a conclusion on whether DIS had contributed to admission prevention. This information was then re-examined in two meetings with at least eight senior psychiatrists present. A consensus opinion was then reached as to whether DIS had contributed to admission prevention in each case.

Results Over 12 months, 30/171 patients (18\%) referred were admitted to hospital. For the subset of 30 referrals examined in detail, DIS contributed to admission avoidance in 21 cases (70\%).

Clinical implications Our evaluation demonstrates that the DIS service is an effective way of preventing admission.

Keywords Out-patient treatment; in-patient treatment; clinical governance; dementia; outcome studies.
Dementia has become a major health concern in older people, with prevalence rates in those over 65 years of age estimated at $7.1 \%$. The overall economic impact of dementia in the UK was costed at $£ 26.3$ billion, with an average annual cost of $£ 32250$ per person, in 2013 . $^{1}$

A quarter of hospital beds are occupied by people with dementia. ${ }^{2}$ Admissions to hospital for patients with dementia are not always preventable but should be avoided where possible, as they are associated with increased length of stay, morbidity and mortality. ${ }^{3}$

The efficacy of crisis resolution and home treatment teams (CRHTTs) in general adult services is reasonably well established, with a Cochrane review confirming that crisis care was acceptable and less expensive. In addition, repeat admissions were avoided and users of crisis services showed greater improvements in their mental state and reported greater satisfaction than those who received standard care. ${ }^{4}$ However, the evidence base is much slimmer for older people and for people with dementia specifically. ${ }^{5,6}$

Cambridge and Peterborough NHS Foundation Trust (CPFT) covers the county of Cambridgeshire (including Peterborough) and some small areas of adjacent counties in England. The total population served by CPFT is approximately 1 million people, of whom 165000 were over the age of 65 at the last census in 2016. There were an estimated 8600 people with dementia in 2016, a number expected to increase to 16110 by $2031 .{ }^{7}$ We have two regional CRHTT services for older people across the county (CRHTT-OP North and CRHTT-OP South), each covering approximately half of the county. To reduce or prevent hospital admissions, our dementia intensive support (DIS) service in CPFT was set up in its current format in 2016. The DIS service forms part of CRHTT-OP South. The role of the CRHTT-OP service is to support both people with dementia and people with functional health problems in crisis at home or in their community settings. The overall aim of CRHTT-OP South/DIS is to reduce or prevent hospital admissions of older people and to facilitate their discharge from hospital.

In this service evaluation, endorsed by management (authors B.R.U. and R.K.), we sought to examine the effectiveness of the DIS service in the South of CPFT, since additional funds were given to the service in 2016. In 2017, the period covered in this study, the team received referrals mainly from general practitioners who referred to a triage 
hub, from the first response service (FRS) - a 24-hour trustwide telephone triage service which accepts self-referral from individuals of all ages - and from liaison psychiatry services. The minimum guaranteed response time by CRHTT-OP South is $24 \mathrm{~h}$ and the maximum is 5 days. CRHTT-OP South usually provides contact with patients for between 2 and 6 weeks. Patients may then be referred onto community mental health teams for ongoing support or back to their general practitioner. Two old age consultants share the work of this team (0.9 whole-time equivalents to CRHTT-OP South) and also share the in-patient work of the functional ward. All clinicians in the team have several years' clinical experience. The team works from 08.00 to 20.00 h, 7 days a week, and operates with two shifts a day; each shift comprises 3-4 community psychiatric nurses, 1-2 community support workers, a team leader (working 09.00-17.00 h on weekdays) and full-time administrative support for the team from 08.30 to $17.00 \mathrm{~h}$ on weekdays. Non-medical clinicians usually undertake the initial assessment of all patients referred to the service, with medical support provided as needed. All patients seen receive a comprehensive psychiatric assessment and risk assessment recorded on our electronic notes. In addition, the interventions by the DIS team are noted in the patients' electronic progress records and letters to the general practitioner (GP). Pharmacological (antidementia drugs, antipsychotics, benzodiazepines and antidepressants) and nonpharmacological interventions for behavioural and psychological symptoms of dementia (BPSD) (typically, exploration of the reasons for the behaviour and suggestions of ways to address it, as well sensory and music stimulation and assistive technology, as described in NICE guidelines from $2018^{8}$ and Alzheimer's Society guidance from $2011^{9}$ ) are employed.

We evaluated, using qualitative and quantitative methodology, whether the involvement of the DIS team did lead to prevention of admission to hospital for older people with dementia.

\section{Method}

This service evaluation was approved by the CPFT governance committee and did not require ethics approval.

We first examined the total referrals to the DIS service over the year (2107) and recorded the number of admissions to medical and psychiatric wards. Exclusion criteria were referrals that the DIS team felt to be inappropriate (e.g. the patient needed a referral to social care or was not deemed to be in a crisis and was referred to the community psychiatric team) or where the patient was not seen because they were admitted to acute hospital before CRHTT-OP South engagement. All patients had a diagnosis of dementia.

We then invited eight senior psychiatrists (consultants and specialist trainees) to support this retrospective study and to examine the notes to see whether the DIS service had prevented admission to hospital. At the time the patients were seen by CRHTT-OP South, some of these doctors were working in CRHTT-OP South but others were working in the community teams or liaison service or had not joined CPFT yet. All patients referred to and contacted by the DIS team in June $2017(n=12)$ and November $2017(n=18)$ were included and the outcome of that contact with the CRHTT during that episode of care was noted, together with the number of days in contact with the DIS. The months were chosen at random. Basic demographic data were collected on the patients and the average length of time spent with the DIS team was calculated. In addition, notes were examined by J.S. R. and L.C. to identify the main reasons for referral and the main interventions offered by the team for each of the 30 patients. The frequencies of these reasons for referral and main interventions recorded were noted. The eight senior psychiatrists were asked to evaluate each patient's notes following referral to CRHTT-OP South in these 2 months to assess whether the DIS team had helped to avoid hospital admission (medical or psychiatric). The notes themselves were not anonymised, but J.S.R. ensured that the clinicians were not given patients from areas that they usually covered clinically, to try to avoid bias in their interpretation, and when these patients were discussed by the group this was done in an anonymous fashion to avoid bias as far as possible. Clinicians had to summarise on a pro forma the issues pertinent to the DIS contact and then reach a conclusion as to whether the DIS service had contributed to 'admission prevention'. In cases where patients had been admitted to hospital, it was straightforward to conclude that admission had not been prevented. In cases where the patient had not been admitted, a qualitative judgement had to be made as to whether, from the type of interventions provided by the DIS team (psychosocial or medical), hospital admission had been avoided. The pro formas regarding the DIS team's involvement were then re-examined collectively in two group governance meetings to provide an 'expert consensus opinion' on whether CRHTT-OP South had contributed to admission prevention, with eight senior psychiatrists present at each meeting.

\section{Results}

Figure 1 shows the total number of patients referred to the DIS service from January to December 2017 and the number of admissions to medical and psychiatric wards from those referrals. There were 171 referrals during that period, 30 of whom (18\%) were admitted, i.e. approximately 1 in every 5 patients referred to the DIS was admitted.

The demographics of the patients whose records were examined in detail by the expert panel are shown in Table 1 . The average length of stay with the DIS team was 19 days (range 4-43 days). The ICD-10 diagnoses were: Alzheimer's disease (14 patients), vascular dementia (5), Alzheimer's of mixed type/atypical (4), dementia not otherwise specified (3), dementia with Lewy bodies (2), alcoholic dementia (1) and frontotemporal dementia (1). Four of the patients with Alzheimer's disease were noted to also have delirium and one patient with Alzheimer's of mixed type was noted to have delirium and alcohol dependence.

The main reasons for referral to the DIS team and their frequency are noted in Table 2. Aggression (verbal and physical) was the most common reason for referral but often several reasons were noted. The key interventions that were recorded in the electronic notes and the frequencies of these are also summarised in Table 2. Combinations of interventions were often offered.

Table 3 shows the number of patients for whom admission was considered to have been avoided by DIS engagement, as well as the average across both months. There were some discrepancies (three in total) between the initial 
Fig. 1 Total referrals accepted by the dementia intensive support (DIS) team over 2017 and numbers admitted to psychiatric and acute (medical) hospitals.

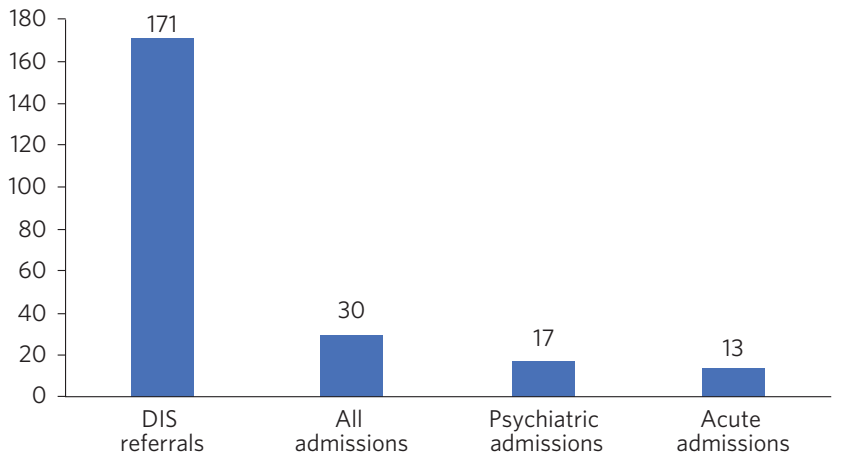

assessor's views and those of the group in deciding whether an admission had in fact been prevented by DIS engagement with the patient. The group view prevailed and is quoted in Table 3. In our qualitative judgement, the DIS service contributed to admission avoidance for $21 / 30$ patients referred (70\%), averaged over the 2 months.

\section{Discussion}

Our service evaluation shows that over a 1-year period only few referrals received by the DIS service were admitted to medical or psychiatric wards (18\%). We conducted a qualitative review of patients referred in 2 months of the year using a panel of senior doctors. These doctors examined 30 referrals to DIS in detail to judge whether DIS had contributed to admission prevention. The panel felt that the DIS service contributed to admission avoidance for $70 \%$ of patients referred to the service in these 2 months.

\section{Strengths and limitations}

Previous criticism of crisis and home treatment studies centres on the definition of a 'crisis' and whether all referrals would in fact meet 'thresholds' for admission. This study sought to circumvent this issue to some extent by examining whether patients in crisis who were seen by CRHTT-OP South had received an intervention from the team which contributed to admission prevention. However, we acknowledge that the discussions that took place among the panel of senior clinicians were of a qualitative nature and subjective. However, the strength of this methodology was that the decisions were not left to a single clinician but were examined by a group of senior clinicians and decision makers in the service.

Although we tried to minimise bias by giving the assessing clinicians patients not from their own teams and by anonymising data when discussed as a group, sometimes

\begin{tabular}{|lcccc|}
\hline Table 1 & \multicolumn{2}{c|}{$\begin{array}{l}\text { Demographics of patients with dementia seen by } \\
\text { the dementia intensive support team over } 2 \\
\text { months in 2017 }\end{array}$} \\
$\begin{array}{lcccc}\text { Sample size, } \\
n\end{array}$ & Male & $\begin{array}{c}\text { Mean age, } \\
\text { years }\end{array}$ & $\begin{array}{c}\text { Age range, } \\
\text { years }\end{array}$ \\
\hline June & 12 & 6 & 83 & $70-96$ \\
\hline November & 18 & 9 & 81 & $66-98$ \\
\hline Combined & 30 & 15 & 82 & $66-98$ \\
\hline
\end{tabular}

Table 2 Reasons for referral to the dementia intensive support (DIS) team and key interventions offered

\begin{tabular}{|c|c|}
\hline & $\begin{array}{l}\text { Frequencies } \\
\text { reported }\end{array}$ \\
\hline \multicolumn{2}{|l|}{$\begin{array}{l}\text { Main reasons for referral to DIS (usually a } \\
\text { combination of reasons) }\end{array}$} \\
\hline Aggression (physical and verbal) & 18 \\
\hline Agitation & 11 \\
\hline $\begin{array}{l}\text { Shouting out/disruptive behaviour/entering } \\
\text { other residents' rooms }\end{array}$ & 10 \\
\hline Worsening hallucinations or delusions & 4 \\
\hline Sexual disinhibition & 3 \\
\hline Depression & 2 \\
\hline $\begin{array}{l}\text { Supporting discharge from ward (acute or } \\
\text { psychiatric) }\end{array}$ & 2 \\
\hline Safeguarding issues & 2 \\
\hline Delirium management & 1 \\
\hline $\begin{array}{l}\text { Suicidal in the context of a new diagnosis of } \\
\text { dementia }\end{array}$ & 1 \\
\hline Carer burnout/stress & 1 \\
\hline \multicolumn{2}{|l|}{$\begin{array}{l}\text { Key interventions offered by DIS team (usually a } \\
\text { combination of interventions) }\end{array}$} \\
\hline Advice and support for carers & 20 \\
\hline Pharmacological interventions for BPSD & 17 \\
\hline Non-pharmacological interventions for BPSD & 16 \\
\hline $\begin{array}{l}\text { Referral for increased social support/different } \\
\text { care home/respite }\end{array}$ & 9 \\
\hline Supportive counselling/advice to the patient & 4 \\
\hline $\begin{array}{l}\text { Recommendation of a change to physical } \\
\text { health medication }\end{array}$ & 4 \\
\hline Admission to psychiatric ward & 4 \\
\hline Admission to acute hospital & 4 \\
\hline $\begin{array}{l}\text { Recommendation of a move to a higher level } \\
\text { of care in the same care home }\end{array}$ & 1 \\
\hline Fall prevention & 1 \\
\hline Delirium assessment management & 1 \\
\hline Educational programme for care home & 1 \\
\hline Benefits advice to carers & 1 \\
\hline
\end{tabular}

BPSD, behavioural and psychological symptoms of dementia. 


\begin{tabular}{|lccc|}
\hline Table 3 & Admission avoidance over 2 months in 2017 \\
& June & November & $\begin{array}{l}\text { Combined (June } \\
\text { and November) }\end{array}$ \\
\hline $\begin{array}{l}\text { Admission } \\
\text { avoided (group } \\
\text { decision) }\end{array}$ & $11 / 12(92 \%)$ & $10 / 18(56 \%)$ & $21 / 30(70 \%)$ \\
\hline
\end{tabular}

clinicians may have recognised the patient under discussion from the particulars of the clinical history, which could have introduced some bias. A further limitation is that this is a naturalistic study and it is possible that not all of the interventions offered were recorded. Only the major interventions identified by the authors examining the notes (J.S.R. and L.C.) have been noted.

\section{The wider evidence base}

We acknowledge that case-control studies are needed to be sure of the efficacy of DIS services. Such studies are very difficult to set up as most services now have some form of crisis or intermediate care service to prevent admission of people with dementia to hospital, and services frequently change structure or function over time.

The most recent systematic review of the literature on crisis team management of dementia in older people, from 2017, describes the results of six cohort studies and one case-control study. ${ }^{5}$ However, several studies include both patients with functional and psychiatric disorders, making direct comparisons with our study more difficult. A positive effect on factors such as reducing the number of hospital admissions, readmissions, length of stay and mortality rates was reported in these studies. However, caution needs to be exercised in interpreting the review's findings as the studies were small, of variable design and sometimes lacking in statistical rigour. ${ }^{5}$ There was only one case-control study (from the USA) in which a non-randomised concurrent control treatment outcome trial was conducted. ${ }^{10}$ This study reported a lower mortality rate, a significant decrease in hospital readmissions (with people remaining in their homes for longer), significant improvements in caregiver outcomes $(P<0.001)$ and fewer neuropsychiatric symptoms for those in the intervention group. It is difficult to be sure how reproducible this service would be in the UK. In addition, the control group did not seem to be similar to the intervention group as they were more likely to die in the first year, suggesting that they may have been a more physically ill group from the outset. Further case-control studies in the UK are needed to establish whether DIS teams are effective in reducing admissions. Our own previous cohort study is one of the few to examine this question before and after the introduction of an ageless CRHTT in the UK, ${ }^{11}$ but it did not examine crisis services for patients with dementia specifically (all crises for older people were included) and other service changes may have affected the result.

\section{Service implications}

Commissioners of our service have enthusiastically endorsed the approach of crisis and home treatment: indeed, 'at home is best' is the top priority for the Cambridgeshire and Peterborough Sustainability and Transformation
Partnership (STP). ${ }^{12}$ This has been reflected in additional investment in DIS teams as one of the key areas for the STP investment fund. This study shows that very few patients referred to our service over the year required hospital admission. Admission cannot always be prevented and of course the reasons for in-patient admission to psychiatric or acute hospital are notoriously complex to analyse (and beyond the scope of this study), involving specifics of particular patients, carers and clinicians. Supportive measures (such as care packages, medication and explanation about the management of delirium) may help to support carers and prevent acute hospital admissions. However, these patients were all referred in crisis and, although some were excluded by our expert panel as not reaching the threshold for the DIS team having contributed to admission prevention, many were helped by interventions from the team. The DIS team has therefore proved to be a worthwhile asset to our service.

\section{About the authors}

Judy S. Rubinsztein is a consultant psychiatrist at Cambridgeshire and Peterborough NHS Foundation Trust, Cambridge; and Department of Psychiatry, University of Cambridge, UK. Catherine Hatfield is a consultant psychiatrist at Cambridgeshire and Peterborough NHS Foundation Trust, Cambridge, UK. Liam High is a personal assistant at Cambridgeshire and Peterborough NHS Foundation Trust, Cambridge, UK. Ramesh Krishnan is CRHTT team leader at Cambridgeshire and Peterborough NHS Foundation Trust, Cambridge, UK. Nikitas A. Arnaoutoglou is a consultant psychiatrist at Cambridgeshire and Peterborough NHS Foundation Trust, Cambridge, UK; Department of Psychiatry, University of Cambridge, UK; and Aristotle University of Thessaloniki, Greece. Panagiota Goulia is a consultant psychiatrist at Cambridgeshire and Peterborough NHS Foundation Trust, Cambridge, UK. Robert Dudas is a consultant psychiatrist at Cambridgeshire and Peterborough NHS Foundation Trust, Cambridge; and Department of Psychiatry, University of Cambridge, UK. Shamim Ruhi is a consultant psychiatrist at Cambridgeshire and Peterborough NHS Foundation Trust, Cambridge, UK. Karel Wildschut is an ST at Cambridgeshire and Peterborough NHS Foundation Trust, Cambridge, UK. Leonidas Chouliaras is a clinical lecturer and ST at Department of Psychiatry, University of Cambridge, UK. Benjamin R. Underwood is a consultant psychiatrist and Clinical Director at Cambridgeshire and Peterborough NHS Foundation Trust, Cambridge and at the Department of Psychiatry, University of Cambridge, UK.

\section{Data availability}

The data associated with the manuscript are available from the corresponding author.

\section{Acknowledgements}

We thank Dr lan Rowbotham, CRHTT consultant in the North of CPFT, for advice and discussion in the early phase of the project, and Christie Walker for administrative support. We thank the librarians at Fulbourn Hospital Library for help with the literature search and sourcing paper.

\section{Author contributions}

All authors made substantial contributions to the conception or design of the work or to the acquisition, analysis or interpretation of data for the work. All authors helped to draft the work or revise it critically for intellectual content. All authors gave final approval of the version to be published and agreed to be accountable for all aspects of the work in accordance with ICMJE criteria.

\section{Declaration of interest}

None.

ICMJE forms are in the supplementary material, available online at https:// doi.org/10.1192/bjb.2020.24. 


\section{References}

1 Prince M, Knapp M, Guerchet M, McCrone P, Prina M, Comas-Herrera A, et al. Dementia UK: Second Edition - Overview: 61. Alzheimer's Society, 2014

2 Lakey R. Counting the Cost - Caring for People with Dementia on Hospital Wards. Alzheimer's Society, 2009.

3 Reynish EL, Hapca SM, De Souza N, Cvoro V, Donnan PT, Guthrie B. Epidemiology and outcomes of people with dementia, delirium, and unspecified cognitive impairment in the general hospital: prospective cohort study of 10,014 admissions. BMC Med 2017; 15(1): 140

4 Murphy SM, Irving CB, Adams CE, Waqar M. Crisis intervention for people with severe mental illnesses. Cochrane Database Syst Rev 2015; 12: CD001087.

5 Streater A, Coleston-Shields DM, Yates J, Stanyon M, Orrell $M$ Maria $D$, et al. A scoping review of crisis teams managing dementia in older people. Clin Interv Aging 2017; 12: 1589-603.

6 Toot S, Devine M, Orrell M. The effectiveness of crisis resolution/home treatment teams for older people with mental health problems: a systematic review and scoping exercise. Int J Geriatr Psychiatry 2011; 26: 1221-30.

7 Cambridgeshire and Peterborough, Older People's Mental Health Delivery Board. Cambridgeshire \& Peterborough All Age Dementia Strategic Plan 2018-2023. Dementia: Everybody's Business: Better Outcomes for People Living with Dementia and their Carers. CPFT, 2018.
8 Pink J, O'Brien J, Robinson L, Longson D. Dementia: assessment, management and support: summary of updated NICE guidance. BMJ 2018; 361: $k 2438$

9 Alzheimer's Society. Optimising Treatment and Care for People with Behavioural and Psychological Symptoms of Dementia: A Best Practice Guide for Health and Social Care Professionals. Alzheimer's Society, 2011.

10 Johnson DK, Niedens M, Wilson JR, Swartzendruber L, Yeager A, Jones $K$. Treatment outcomes of a crisis intervention program for dementia with severe psychiatric complications: the Kansas bridge project. Gerontologist 2013; 53: 102-12.

11 Dibben C, Saeed H, Stagias K, Khandaker GM, Rubinsztein JS. Crisis resolution and home treatment teams for older people with mental illness. Psychiatr Bull 2008; 32: 268-70.

12 Cambridgeshire and Peterborough Clinical Commissioning Group. Cambridgeshire and Peterborough Sustainability and Transformation Plan Summary - November 2016: How Health and Care Services in Cambridgeshire and Peterborough are Changing. Cambridgeshire and Peterborough Sustainability and Transformation Partnership. Available from: https://www.fitforfuture.org.uk/what-were-doing/publications/.

\title{
ORIGINAL PAPER
}

\section{Psychoeducation and motivational interviewing to reduce relapses and increase patients' involvement in antipsychotic treatment: interventional study}

\author{
Gabriella Bröms, ${ }^{1}$ Lindah Cahling, ${ }^{2}$ Anders Berntsson, ${ }^{2}$ Lars Öhrmalm ${ }^{2,3}$ ๑
}

BJPsych Bulletin (2020) 44, 265-268, doi:10.1192/bjb.2020.28

${ }^{1}$ Unit of Clinical Epidemiology, Centre for Pharmacoepidemiology, Karolinska Institutet, Stockholm, Sweden; 2 PRIMA Child and Adult Psychiatry, Stockholm Sweden; ${ }^{3}$ Department of Medicine, Solna, Karolinska Institutet, Stockholm Sweden

Correspondence to Lars Öhrmalm (lars.ohrmalm@prima.se)

First received 17 May 2019, final revision 7 Feb 2020, accepted 26 Feb 2020

(C) The Authors 2020. This is an Open Access article, distributed under the terms of the Creative Commons Attribution licence (http://

creativecommons.org/licenses/by/4.0/) which permits unrestricted reuse, distribution, and reproduction in any medium, provided the original work is properly cited.
Aims and method To assess whether the combination of motivational interviewing and psychoeducation affects relapse rate and stimulates involvement of people with psychosis in their treatment. We conducted an interventional study including patients with schizophrenia or schizoaffective disorder treated with oral antipsychotics, without previous experience of long-acting injectable antipsychotics (LAIs). They were randomised to either psychoeducation with motivational interviewing or a control group. Hospital admissions 18 months before and after the intervention, and switches to LAls 18 months after the intervention, were recorded.

Results The two groups each comprised 101 participants. Fourteen from the intervention group and seven from the control group switched to LAls. Five in the intervention group instigated the switch themselves, compared with zero controls $(P=0.06)$. Fourteen in the intervention group were readmitted to hospital during follow-up, compared with 23 in the control group $(P=0.14)$.

Clinical implications Psychoeducation with motivational interviewing may increase patients' involvement in their treatment and reduce the relapse frequency.

Keywords Motivational interviewing; psychoeducation; schizophrenia; antipsychotics; adherence. 